\title{
On the Mode of Action of 11-deoxycorticosterone on the Metabolism of Trichophyton rubrum
}

\author{
By F. W. CHATTAWAY AND J. D. TOWNSLEY \\ Department of Biochemistry, University of Leeds \\ AND A. J. E. BARLOW \\ Department of Dermatology, The Royal Infirmary, Huddersfield
}

(Received 14 May 1962)

\begin{abstract}
SUMMARY
The mechanism by which 11-deoxycorticosterone (DOC) inhibits the growth of Trichophyton rubrum was studied by examining the effects of this steroid upon metabolism by the intact mycelium. This compound inhibited the rate of endogenous respiration and the rate of uptake of glucose from the medium, but no evidence was found for the release of intracellular components from the mycelium. Incubation of mycelium in the presence of $\left[{ }^{14} \mathrm{C}\right]$-glucose resulted in the incorporation of $\left[{ }^{14} \mathrm{C}\right]$ into 37 components within $3 \mathrm{~min}$. in aqueous ethanol extracts of mycelium, although $98 \%$ of the $\left[{ }^{14} \mathrm{C}\right]$ in these extracts was contained in fructose, alanine, phosphorylated compounds and an unidentified compound. Incubation in the presence of 11-deoxycorticosterone resulted in a marked change in distribution, with decrease of the labelling of the phosphorylated compounds and fructose and increases in the labelling of the alanine and unidentified component. The results show considerable similarity to the effects of agents such as 2,4-dinitrophenol on yeast metabolism and suggest that the uncoupling of phosphorylation from oxidation may be one result of the action of i1-deoxycorticosterone on T. rubrum.
\end{abstract}

\section{INTRODUCTION}

Previous work (Chattaway, Townsley \& Barlow, 1959, 1962) showed that 11deoxycorticosterone (DOC) was one of the most potent of a group of steroids which inhibited the growth of Trichophyton rubrum, strain OS. The present paper describes studies designed to throw light upon the mechanism by which DOC exerts its inhibitory action on the growth of this fungus. A preliminary report of this work has been published (Townsley, Chattaway \& Barlow, 1961).

\section{METHODS}

Organism. The organism used was Trichophyton rubrum, strain OS, and mycelial pads were grown at $33^{\circ}$ on Sabouraud liquid medium or on the defined medium previously described (Chattaway et al. 1959).

Relation of DOC concentration to mycelial weight. The previously reported growth studies showed that $50 \%$ inhibition of growth of Trichophyton rubrum, strain OS, was given by $0.15 \mathrm{mg}$. DOC/10 ml. medium. This was the inhibition of the growth of an inoculum equivalent to $1 \mathrm{mg}$. dry weight organism or $6 \mathrm{mg}$. wet weight (i.e. 
mycelium dried between sheets of filter paper), giving a ratio of weight of DOC required to cause $50 \%$ inhibition of growth to that of mycelial wet weight of $1: 40$. In the following experiments on the effect of DOC on glucose uptake, endogenous respiration, release of cell components and metabolism of glucose this ratio was maintained.

Uptake of glucose. For studies of the uptake of uniformly labelled $\left.{ }^{14} \mathrm{C}\right]$-glucose by mycelium, the fungus was grown in Sabouraud medium for 7 days, washed three times with water and dried between sheets of filter paper; $0 \cdot 15 \mathrm{~g}$. portions of this mycelium were then suspended in water $(4.5 \mathrm{ml}$.) with the addition of DOC (final concentration $4.5 \mathrm{~mm}$ ) as required. The DOC was added to the sterile flasks in chloroform ethanol $(1+1$ by vol.) solution and the solvent evaporated before addition of the medium. The mycelial suspensions were incubated for $1 \mathrm{hr}$. at room temperature and then $1 \cdot 0 \mu$ c. $\left[{ }^{14} \mathrm{C}\right]$-glucose (Radiochemical Centre, Amersham, Buckinghamshire) added (final glucose concentration $0.053 \mathrm{M}$ ).

Respiration determinations were made by the conventional Warburg techniques, the organism being grown on the defined medium for 8 days, washed twice with $0.0133 \mathrm{M}$-phosphate buffer ( $\mathrm{pH} \mathrm{6.8)}$ ) and suitable amounts suspended in the buffer. Oxygen uptake was measured for $1 \mathrm{hr}$. and then glucose (to final $40 \mathrm{~mm}$ ) and/or DOC (to final $0.76 \mathrm{~mm}$ ) in $\mathbf{0 . 5} \mathrm{ml}$. phosphate buffer added. Oxygen uptake was followed for $1 \mathrm{hr}$. further.

Metabolism of $\left.{ }^{[4} \mathrm{C}\right]$-glucose. This was studied with mycelial pads grown on Sabouraud medium for 7 days, then washed three times with water, dried between filter papers and weighed portions $(0.5 \mathrm{~g}$.) suspended in $1.0 \mathrm{ml}$. water or aqueous DOC (7.6 mM.) suspension. After incubation for $1 \mathrm{hr}$. at room temperature the contents of each flask were transferred to a Pyrex sintered glass filter funnel (No. 4, $3 \mathrm{~cm}$. diameter) and connected to, but shut off from, a filter pump. A solution containing $300 \mu \mathrm{l}$. of $\left[{ }^{14} \mathrm{C}\right]$-glucose $(33 \cdot 3 \mu \mathrm{c}$., $18 \mu$ mole, final glucose concentration, $1.8 \mathrm{mM}$ ) was added to each filter funnel and the funnel closed by a rubber bung pierced by a glass tube fitted with a tap. After the required incubation period the rubber bung was removed, the supernatant fluid removed by suction and the funnel rapidly transferred to another filter flask and boiling $80 \%(\mathrm{v} / \mathrm{v})$ aqueous ethanol $(5 \mathrm{ml}$.) poured on to the mycelium, the bung then being replaced. The incubation time was taken to be that period from the addition of the glucose until the addition of ethanol. Extraction was continued for $90 \mathrm{~min}$., the extract sucked off and two more extractions for $60 \mathrm{~min}$. periods made with $5 \mathrm{ml}$. portions of boiling $20 \%(\mathrm{v} / \mathrm{v})$ aqueous ethanol. The combined extracts were evaporated to dryness in vacuo at $40^{\circ}$ and when required the supernatant fluids from the initial incubation with $\left[{ }^{14} \mathrm{C}\right]$-glucose were similarly concentrated. The residues were washed three times with ether $(5 \mathrm{ml}$.) to remove residual DOC since this was found to cause streaking on chromatograms; the final ether-free residue was dissolved in $2.5 \mathrm{ml} .50 \%(\mathrm{v} / \mathrm{v})$ aqueous ethanol.

Paper chromatography. The radioactive substances in the concentrated cell extracts and supernatant fluids were analysed by two-dimensional descending paper chromatography on $46 \times 57 \mathrm{~cm}$. sheets of Whatman No. 4 filter paper. The phenol + formic acid water system of Kornberg (1958) was used in the first dimension and $n$-butanol + propionic acid + water $(46 \cdot 8+22 \cdot 0+30 \cdot 1$ by vol.) in the second (Benson et al. 1950). Of the final $2.5 \mathrm{ml}$. of concentrated extract, $0.2 \mathrm{ml}$. was chromato- 
graphed and the radioactive substances on the chromatogram located by radioautography with Kodirex X-ray film (Kodak Ltd.). The radioactivity in each spot was counted directly by means of a G.E.C. Geiger-Müller tube, type E.H.M. 25 operating at $1480 \mathrm{~V}$.

Radioactive spots on the chromatograms were identified provisionally by their chromatographic positions in the above solvent systems. This was confirmed by co-chromatography with authentic materials in these systems and in an ethyl acetate + water + pyridine system $(4+4+1$, by vol.; see Jermyn \& Isherwood, 1949) and the $n$-propanol + ethyl acetate + water $(7+1+2$, by vol.) system of Baar $\&$ Bull (1953) for carbohydrate materials. For ninhydrin-reacting substances $n$-butanol + acetone + diethylamine + water $(10+10+2+5$, by vol.; Hardy, Holland \& Naylor, $1955)$ and ethanol + ammonia $(0 \cdot 880)+$ water $(180+10+10$; by vol.; Smith, 1960) systems were used. The presence of orthomonophosphate esters was shown by treatment of chromatogram eluates with alkaline phosphatase (Light \& Co.) by the method of Heppel (1955).

Chemical estimations. Amino acids present in mycelial supernatant fluids were estimated by determination of total $\alpha$-amino nitrogen by the method of Moore $\&$ Stein (1954). Inorganic phosphate was estimated by the method of Fiske \& Subba Row (1925).

\section{RESULTS}

\section{Effect of 11-deoxycorticosterone on endogenous respiration}

DOC has been shown to inhibit the respiration of baker's yeast in the presence of glucose (Shacter, 1949) and of germinating conidia of Neurospora crassa in the presence of sucrose (Lester, Stone \& Hechter, 1958); in both cases endogenous respiration was either stimulated or unaffected. Many workers have demonstrated the high endogenous respiration rate of dermatophytes and the virtual absence of response in respiration rate to added substrates. In common with these findings the mycelium of Trichophyton rubrum used in this work showed no response to added glucose, and the endogenous respiration rate was linear for at least $2 \mathbf{h r}$. The effect of DOC on the endogenous respiration is shown in Fig. 1, the DOC being added after $1 \mathrm{hr}$. incubation of the mycelium in phosphate buffer. The rate of respiration is seen to be inhibited $50 \%$.

\section{Effect of DOC on the release of cytoplasmic contents}

Fatty acids and certain detergents are known to be fungistatic and to inhibit fungal respiration by action on the cell wall, with resulting loss of intracellular components. Since certain steroids exhibit surface activity, the possibility that DOC exerted its inhibitory effect on growth and respiration of Trichophyton rubrum by this means was examined by comparing the release of inorganic phosphate and amino acids from the mycelium into the medium in the presence of cetyltrimethylammonium bromide (CTAB) or DOC, with that produced in the presence of water alone. The results, Fig. 2, show that CTAB released appreciable amounts of both materials, while DOC promoted no release beyond that which occurred with water alone. Thus DOC did not appear to exert its inhibition by virtue of a disrupting action on the fungal wall. 


\section{The effect of 11-deoxycorticosterone on glucose metabolism}

It appeared possible that the effects of DOC on growth, glucose uptake and endogenous respiration by Trichophyton rubrum might be explicable in terms of an effect on energy availability; therefore its overall effect on the metabolism of $\left[{ }^{14} \mathrm{C}\right]$ glucose was studied. The experiments were similar to those in which Moses (1958) studied the effects of starvation, ammonia and azide on the incorporation pattern of $\left[{ }^{14} \mathrm{C}\right]$-glucose in Zygorhynchus moelleri and in which Moses \& Smith (1960) investigated the effects of uncoupling agents on glucose metabolism in baker's yeast.

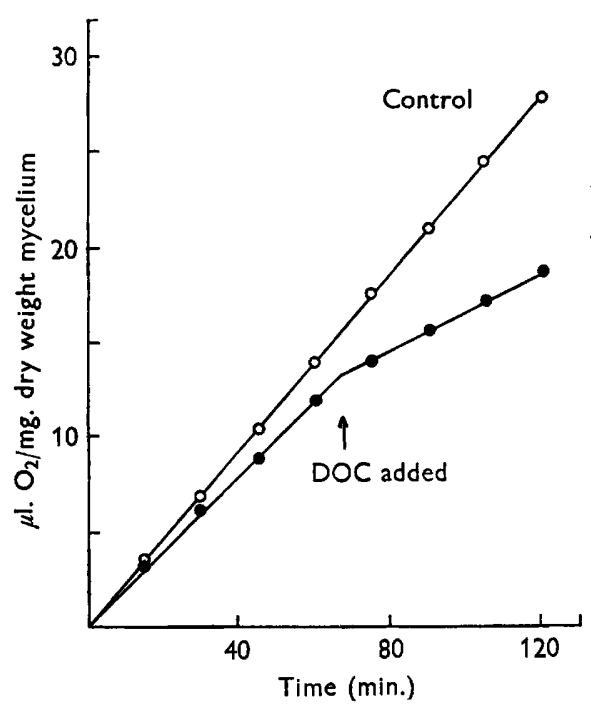

Fig. 1

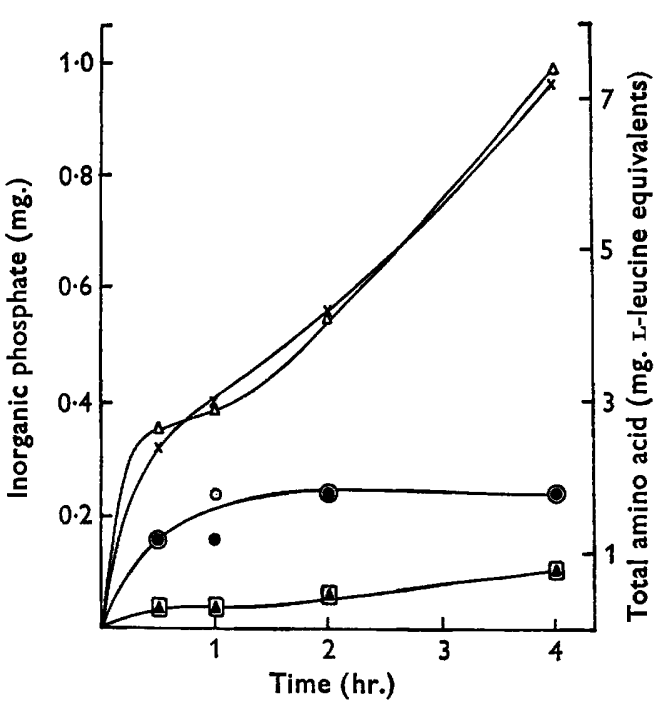

Fig. 2

Fig. 1. Inhibition of endogenous respiration of Trichophyton rubrum by 11-deoxycorticosterone (DOC). Washed mycelium was suspended in $0.0133 \mathrm{M}$-phosphate buffer (pH 6.8). DOC suspension in phosphate buffer $(0.5 \mathrm{ml}$.) was added as shown, to final concentration $0 \cdot 76 \mathrm{~mm}$.

Fig. 2. Release of intracellular components from Trichophyton rubrum by 11-deoxycorticosterone (DOC) and by cetyltrimethylammonium bromide (CTAB). Washed mycelium $(0.4 \mathrm{~g}$. suspended in $60 \mathrm{ml}$. of either $1.0 \mathrm{mM}$-DOC suspension, $0.27 \mathrm{~mm}$-CTAB or water), was incubated for $4 \mathrm{hr}$. at room temp. Samples $(4 \mathrm{ml}$.) were withdrawn at intervals. Amino acids released in presence of $\operatorname{DOC}(\Delta), \operatorname{CTAB}(\Delta)$, water $(\square)$. Phosphate released in presence of DOC $(\Theta)$, CTAB $(x)$, water $(O)$.

The incorporation of $\left[{ }^{14} \mathrm{C}\right]$-glucose into the aqueous ethanol fraction was determined as described in Methods. The incorporation of $\left[{ }^{14} \mathrm{C}\right]$ into this fraction after exposure

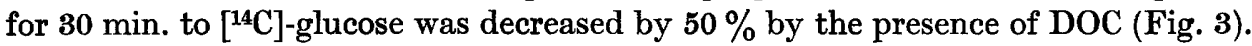
A typical chromatogram showing diagrammatically the pattern of incorporation into compounds of the aqueous ethanol extract from normal mycelium of $T$. rubrum is shown in Fig. 4. This was obtained after exposure of mycelium to $\left[{ }^{14} \mathrm{C}\right]-$ glucose for $3 \mathrm{~min}$. and shows that radioactivity was present in $\mathbf{3 7}$ compounds besides the glucose. Similar experiments were carried out to determine the effect of DOC on the pattern of incorporation after exposure of mycelium to $\left[{ }^{14} \mathrm{C}\right]$-glucose for 10 , 
60,180 and $1800 \mathrm{sec}$. The radioactivity of each spot was determined in the resulting chromatograms and the values expressed as a percentage of total $\left[{ }^{14} \mathrm{C}\right]$ other than glucose incorporated into the aqueous ethanol soluble fraction (Table 1).

Table 1. Incorporation of $\left[{ }^{14} \mathrm{C}\right]$ from $\left[{ }^{14} \mathrm{C}\right]$-glucose by Trichophyton rubrum strain $\mathrm{OS}$ in the absence and presence of 11-deoxycorticosterone (DOC)

Values given are percentage of total $\left[{ }^{14} \mathrm{C}\right]$ (other than glucose) incorporated into the aqueous ethanol soluble fraction of the organism during the incubation periods shown. Spot nos. refer to Fig. 4.

Time of incubation (sec.)

$\overbrace{10}^{60} \quad 180 \quad 1800$

\begin{tabular}{|c|c|c|c|c|c|c|c|c|}
\hline \multirow{2}{*}{$\begin{array}{c}\text { Spot } \\
\text { no. }\end{array}$} & Control & DOC & Control & DOC & Control & DOC & Control & DOC \\
\hline & \multicolumn{8}{|c|}{ Incorporation of ${ }^{14} \mathrm{C}(\%)$} \\
\hline 1 & 0.72 & 0.00 & 0.95 & $0 \cdot 00$ & $0 \cdot 88$ & 0.00 & 0.45 & $0 \cdot 60$ \\
\hline 2 & 0.46 & 0.00 & 0.00 & $0 \cdot 00$ & $0 \cdot 81$ & 0.00 & 0.52 & 0.00 \\
\hline $\mathbf{3}$ & 0.00 & 0.00 & 0.00 & 0.00 & 0.00 & $0 \cdot 00$ & $1 \cdot 48$ & 0.00 \\
\hline 4 & $8 \cdot 84$ & $0 \cdot 59$ & 9.32 & $\mathbf{3} \cdot \mathbf{2 3}$ & $17 \cdot 75$ & $1 \cdot 94$ & $11 \cdot 94$ & $1 \cdot 28$ \\
\hline 5 & 0.59 & 0.00 & 0.00 & 0.00 & $0 \cdot 81$ & 0.00 & 0.58 & 0.00 \\
\hline 6 & 0.00 & 0.00 & 0.00 & $0 \cdot 00$ & 0.54 & 0.00 & 0.58 & $1 \cdot 75$ \\
\hline 7 & 0.00 & 0.59 & 0.00 & 0.00 & 0.47 & 0.00 & 0.00 & 0.00 \\
\hline 8 & 0.00 & $0 \cdot 00$ & $1 \cdot 01$ & 0.00 & 0.95 & 0.00 & 0.71 & 0.00 \\
\hline 9 & 0.00 & $0 \cdot 98$ & 0.00 & 0.00 & 0.00 & 0.00 & 0.00 & 0.00 \\
\hline 10 & 0.00 & $3 \cdot 14$ & 0.00 & 0.00 & 0.54 & $0 \cdot 00$ & 0.00 & 0.00 \\
\hline 11 & 0.00 & $0 \cdot 00$ & 0.61 & 0.92 & 0.00 & $1 \cdot 61$ & 0.00 & 0.00 \\
\hline 12 & 0.39 & $1 \cdot 11$ & 0.00 & 0.99 & 0.00 & 0.74 & 0.00 & 0.00 \\
\hline 13 & $1 \cdot 24$ & $2 \cdot 29$ & $1 \cdot 16$ & $\mathbf{3} \cdot 90$ & 0.47 & $0 \cdot 00$ & 0.00 & 0.00 \\
\hline 14 & 4.77 & $\mathbf{3} \cdot 73$ & $0 \cdot 61$ & $\mathbf{9} \cdot \mathbf{2 4}$ & 0.74 & $13 \cdot 50$ & $0 \cdot 45$ & $0 \cdot 00$ \\
\hline 15 & 0.00 & 4.57 & $0 \cdot 41$ & 0.00 & 0.47 & 0.00 & 0.00 & 0.00 \\
\hline 16 & 5.55 & $8 \cdot 56$ & 0.88 & $2 \cdot 38$ & 1.08 & $2 \cdot 28$ & 0.00 & 0.00 \\
\hline 17 & $1 \cdot 50$ & $2 \cdot 88$ & $1 \cdot 29$ & $0 \cdot 00$ & 0.68 & 3.01 & $0 \cdot 84$ & 0.00 \\
\hline 18 & $1 \cdot 24$ & $2 \cdot 42$ & 0.00 & $1 \cdot 52$ & 0.00 & $0 \cdot 87$ & 0.00 & 0.00 \\
\hline 19 & 1.24 & $4 \cdot 44$ & 0.75 & 0.00 & 0.41 & $0 \cdot 67$ & $0 \cdot 00$ & 0.00 \\
\hline 20 & $20 \cdot 30$ & 3.72 & 0.00 & 0.00 & 0.00 & 0.00 & 0.00 & 0.00 \\
\hline 21 & 0.00 & $0 \cdot 00$ & 0.48 & 0.00 & 0.00 & 0.00 & 0.00 & 0.00 \\
\hline 22 & 0.65 & $2 \cdot 29$ & $0 \cdot 00$ & 0.00 & $0 \cdot 00$ & $0 \cdot 00$ & 0.00 & 0.00 \\
\hline 23 & $11 \cdot 63$ & $13 \cdot 70$ & 3.13 & $5 \cdot 28$ & $2 \cdot 64$ & $2 \cdot 16$ & 0.00 & 0.00 \\
\hline 24 & $9 \cdot 34$ & $7 \cdot 06$ & $37 \cdot 55$ & $31 \cdot 40$ & $55 \cdot 20$ & $28 \cdot 10$ & $67 \cdot 70$ & $51 \cdot 40$ \\
\hline 25 & $1 \cdot 63$ & $3 \cdot 14$ & 0.00 & 0.92 & 0.47 & 0.67 & 0.00 & 0.00 \\
\hline 26 & $4 \cdot 44$ & $6 \cdot 21$ & 1.77 & $7 \cdot 07$ & 1.01 & $7 \cdot 63$ & 0.00 & 0.00 \\
\hline 27 & 0.85 & 0.79 & 0.00 & 0.92 & 0.00 & 0.42 & $0 \cdot 00$ & 0.00 \\
\hline 28 & 0.00 & 0.00 & 0.48 & $0 \cdot 40$ & $0 \cdot 00$ & 0.00 & 0.00 & 0.00 \\
\hline 29 & $4 \cdot 12$ & $6 \cdot 92$ & 0.82 & $2 \cdot 44$ & $1 \cdot 76$ & $2 \cdot 01$ & 0.00 & 0.00 \\
\hline 30 & $\mathbf{1} \cdot \mathbf{3 1}$ & $1 \cdot 44$ & 0.54 & $5 \cdot 51$ & 0.00 & $2 \cdot 68$ & 0.00 & 0.00 \\
\hline $\mathbf{3 1}$ & 2.02 & $2 \cdot 48$ & $10 \cdot 80$ & 6.08 & $6 \cdot 42$ & $20 \cdot 97$ & $13 \cdot 10$ & $27 \cdot 00$ \\
\hline 32 & $1 \cdot 44$ & 1.96 & $0 \cdot 88$ & $2 \cdot 31$ & $0 \cdot 68$ & $2 \cdot 07$ & 0.00 & $0 \cdot 00$ \\
\hline 33 & 1.05 & $1 \cdot 44$ & 0.00 & $0 \cdot 00$ & 0.00 & 0.74 & 0.00 & 0.00 \\
\hline 34 & 1.50 & $1 \cdot 83$ & 0.00 & 0.00 & 0.47 & $\mathbf{1} \cdot \mathbf{3 4}$ & 0.00 & 0.00 \\
\hline 35 & $11 \cdot 70$ & $11 \cdot 50$ & 26.95 & $13 \cdot 48$ & $4 \cdot 66$ & $6 \cdot 75$ & 1.03 & $16 \cdot 90$ \\
\hline 36 & $1 \cdot 60$ & $0 \cdot 39$ & 0.00 & 0.00 & 0.00 & $0 \cdot 00$ & 0.00 & 0.00 \\
\hline 37 & 0.00 & 0.00 & 0.00 & $2 \cdot 24$ & 0.00 & 0.00 & 0.45 & 0.81 \\
\hline
\end{tabular}

\section{Identification of $\left[{ }^{14} \mathrm{C}\right]$ labelled compounds}

The identification of labelled compounds in the aqueous ethanol extracts was attempted by a study of sugars, amino acids and phosphates present in extracts from unlabelled mycelium, prepared under conditions identical with those used in 
the $\left[{ }^{14} \mathrm{C}\right]$ incorporation experiments, by using the chromatographic techniques described. The only labelled carbohydrate compounds detected were glucose (spot 0 , Fig. 4) and fructose (spot 24). Seventeen compounds which reacted with ninhydrin were present, of which only one appeared to be labelled; this was identified as alanine (spot 31). A consideration of the chromatographic maps of Bassham \& Calvin (1957) suggested that spots 1-8 represented phosphorylated compounds, due allowance being made for the fact that acidic compounds show increased $\boldsymbol{R}_{\boldsymbol{r}}$ values

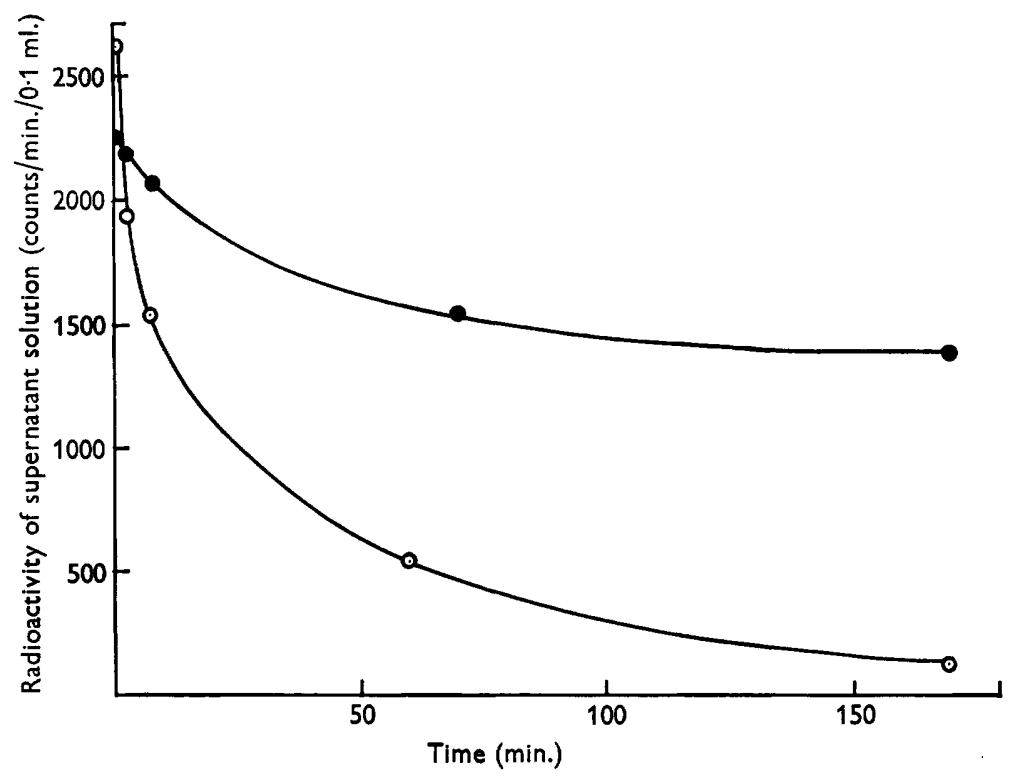

Fig. 3. Inhibition by 11-deoxycorticosterone of the uptake of $\left[{ }^{14} \mathrm{C}\right]$-glucose by Trichophyton rubrum. Two portions of washed mycelium $(0 \cdot 15 \mathrm{~g})$ suspended in $4.5 \mathrm{ml}$. water, one containing DOC $(7.5 \mathrm{mg}$.) in suspension, were incubated for $1 \mathrm{hr}$. at room temp. $\left[{ }^{14} \mathrm{C}\right]$-glucose $(0.5 \mathrm{ml}$. containing $1 \mu \mathrm{c}$; f final concentration $0.053 \mu \mathrm{M})$ was added to each flask. Samples $(0.1 \mathrm{ml}$.) of the suspending medium were withdrawn at intervals for determination of radioactivity. Mycelium with DOC (๑), control (O).

in the phenol + water + formic acid solvent system of Bassham \& Calvin. This was confirmed for spots 4 and 6 , by showing them to be orthomonophosphate esters by elution and treatment with alkaline phosphatase followed by further study of the chromatographic properties of the products.

\section{Effect of DOC on $\left[{ }^{14} \mathrm{C}\right]$ distribution}

It can thus be seen from Table 1 that in normal mycelium after $30 \mathrm{~min}$. exposure to $\left[{ }^{14} \mathrm{C}\right]$-glucose $98 \%$ of the $\left[{ }^{14} \mathrm{C}\right]$ incorporated was present in fructose $(67 \cdot 7 \%)$, alanine $(13 \cdot 1 \%)$, phosphorylated compounds $(16 \cdot 3 \%)$ and an unidentified compound spot $35(1.0 \%)$. After exposure to DOC the above compounds still accounted for over $98 \%$ of the $\left[{ }^{14} \mathrm{C}\right]$ incorporated but the distribution of radioactivity changed appreciably, being fructose $(51 \cdot 4 \%)$, alanine $(27 \%)$, phosphorylated compounds $(3.6 \%)$ and spot $35(16.9 \%)$. The effect on the phosphorylated compounds was marked since after exposure to DOC only 3 such compounds were labelled and the decrease in percentage incorporation into this fraction was apparent from the 
shortest time of exposure to the $\left[{ }^{14} \mathrm{C}\right]$-glucose. Since it was shown above that DOC did not bring about the release of intracellular compounds it appears unlikely that the effect on the uptake of glucose was the result of a direct action of DOC on the permeability of the cell wall; this conclusion was supported by a chromatographic study of the radioactivity of compounds in the supernatant solutions.

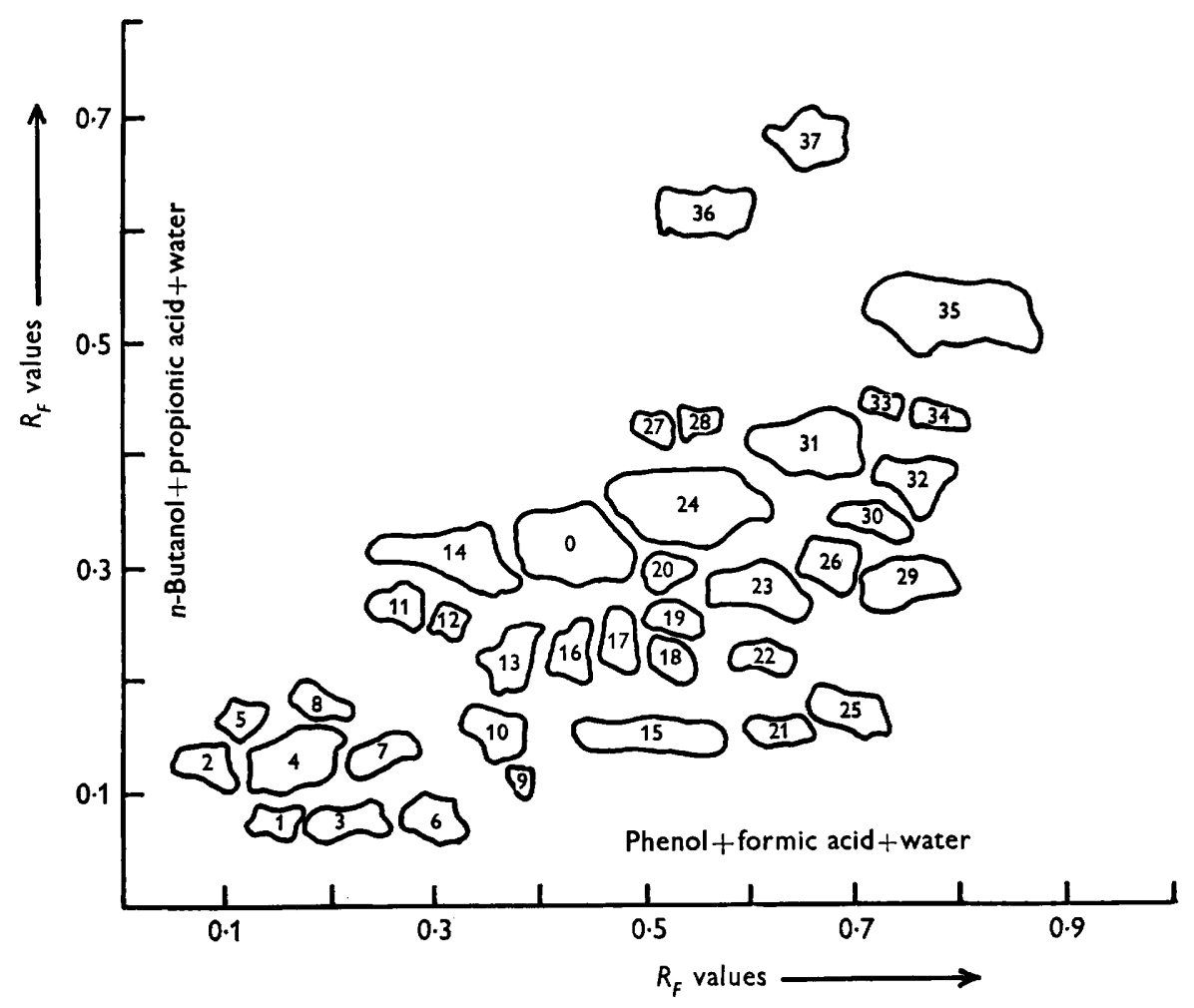

Fig. 4. Incorporation of $\left[{ }^{14} \mathrm{C}\right]$ into cytoplasmic components of Trichophyton rubrum. Diagrammatic representation of labelled areas (number 1 to 37 ) on a 2-dimensional chromatogram obtained from the aqueous ethanol extract of normal mycelium $(0.5 \mathrm{~g})$ exposed for $3 \mathrm{~min}$. to $\left[{ }^{14} \mathrm{C}\right]$-glucose $(\mathbf{3 3 . 3} \mu \mathrm{c} ; 18 \mu$ mole, final glucose concentration $1.8 \mathrm{~mm})$. Spot $0=$ glucose.

\section{DISCUSSION}

The inhibitory effects of DOC on growth, endogenous respiration and uptake of glucose by Trichophyton rubrum and its effect upon the pattern of distribution of ${ }^{\left[{ }^{4} \mathrm{C}\right]-g l u c o s e}$ within the mycelium show results similar to those obtained by Moses \& Smith (1960) in their study of the effects of uncoupling agents on yeast metabolism. Thus they found that 2,4-dinitrophenol (DNP) inhibited endogenous respiration and respiration in the presence of exogenous substrates, and also decreased the incorporation of $\left[{ }^{14} \mathrm{C}\right]$-glucose by over $50 \%$; incorporation of $\left[{ }^{14} \mathrm{C}\right]$ into phosphorylated compounds and free sugars (primarily trehalose) was decreased but incorporation into amino acids (mainly glutamic acid and alanine) was increased. A similarity between the action of DNP and DOC was shown by Conner $(1957,1959)$ with Tetrahymena piriformis; both compounds inhibited growth of this organism 
and the inhibition was annulled by stigmasterol. DOC has been reported to inhibit the NADH-cytochrome $c$ reductase of heart muscle (Mahler, 1955) and of Saccharomyces fragilis, Escherichia coli and Bacillus subtilis (Yielding \& Tomkins, 1959), an effect which would impede the formation of ATP and thus interfere with energyrequiring reactions.

There is thus evidence which suggests a similarity between the action of DOC in Trichophyton rubrum and that of uncoupling agents in other organisms, suggesting that one result of the action of DOC on T. rubrum is the uncoupling of oxidative phosphorylation. This does appear to be contrary to the findings of Lester et al. (1958) and of Lester \& Hechter (1959) in their studies of the action of DOC on Neurospora crassa. They found that growth, oxygen uptake in the presence of exogenous substrate, and uptake of sugars, amino acids and rubidium were inhibited, but that endogenous respiration was not affected; the distribution of sodium within the cell was also affected by DOC. They postulated that the effect of DOC was upon the binding of ions within the cell and not upon the energy-requiring reactions associated with uptake of substrates.

We are grateful to the Wellcome Trust for a maintenance grant to one of us (J.D.T.) and a contribution towards the cost of this work; also to Messrs E. R. Squibb for a grant towards the cost of radioactive materials.

\section{REFERENCES}

BaAR, S. \& Bull, J. P. (1953). Salt interference in sugar chromatography of urine. Nature, Lond. 172, 414.

Bassham, J. A. \& Calvin, M. (1957). In The Path of Carbon in Photosynthesis. New Jersey: Prentice Hall Inc.

Benson, A. A., Bassham, J. A., Calvin, M., Goodale, T. C., HaAs, V. A. \& Stepka, W. (1950). The path of carbon in photosynthesis. V. Paper chromatography and radioautography of the products. J. Amer. Chem. Soc. 72, 1710.

Chattaway, F. W., Townsley, J. D. \& Barlow, A. J. E. (1959). Effect of steroids and related compounds on the growth of dermatophytes. Nature, Lond. 184, 1731.

Chattaway, F. W., Townsley, J. D. \& Barlow, A. J. E. (1962). The effect of certain steroids upon the growth of Trichophyton rubrum. J. gen. Microbiol. 28, 437.

CoNNER, R. L. (1957). Interaction of stigmasterol and 2,4-dinitrophenol in the growth of Tetrahymena piriformis. Science, 126, 698.

CoNNER, R. L. (1959). Inhibition of growth of Tetrahymena piriformis by certain steroids. J. gen. Microbiol. 21, 180.

Fiske, C. H. \& SubbaRow, Y. (1925). The colorimetric determination of phosphorus. J. biol. Chem. 66, 375.

Hardy, T. L., Holland, D. O. \& Naylor, J. H. C. (1955). One-phase solvent mixtures for the separation of amino acids. Analyt. Chem. 27, 971.

Heppex, L. A. (1955). In Methods of Enzymology, 2, 530. Ed. by S. P. Colowick \& M. O. Kaplan. New York: Academic Press Inc.

JERMYN, M. A. \& Isherwood, F. A. (1949). Improved separation of sugars on the paper partition chromatogram. Biochem. J. 44, 402.

Kornberg, H. L. (1958). The metabolism of $\mathrm{C}_{2}$ compounds in micro-organisms. 1. The incorporation of $\left.2-{ }^{14} \mathrm{C}\right]$ acetate by Pseudomonas fluorescens, and by a corynebacterium, grown on ammonium acetate. Biochem. J. 68, 535.

Lester, G. \& Hechter, O. (1959). The relationship of sodium, potassium and deoxycorticosterone in Neurospora crassa. Proc. nat. Acad. Sci., Wash. 45, 1792. 
Lester, G., Stone, D. \& Hechter, O. (1958). The effect of deoxycorticosterone and other steroids on Neurospora crassa. Arch. Biochem. Biophys. 75, 196.

Mahler, H. R. (1955). In Methods in Enzymology, 2, 688. Ed. by S. P. Colowick \& M. O. Kaplan. New York: Academic Press Inc.

Moore, S. \& STEIN, W. H. (1954). A modified ninhydrin reagent for the photometric determination of amino acids and related compounds J. biol. Chem. 211, 907.

Moses, V. (1958). $\left[{ }^{14} \mathrm{C}\right]$-glucose metabolism in fungal cells. J. gen. Microbiol. $20,184$.

Moses, V. \& Smrth, M. J. H. (1960). Uncoupling reagents and metabolism. 2. Effects of 2,4-dinitrophenol and salicylate on glucose metabolism in yeast. Biochem.J. 76, 585.

Shacter, B. (1949). Increase in yeast respiration in presence of several steroids and diethylstilboestrol. Arch. Biochem. 23, 321.

Sмrтн, I. (1960). In Chromatographic and Electrophoretic Techniques, vol. 1. London: Wm. Heinemann Medical Books Ltd.

Townsley, J. D., Chattaway, F. W. \& Barlow, A. J. E. (1961). The effect of 11-deoxycorticosterone on carbohydrate metabolism in Trichophyton rubrum. Biochem. J. 81, $14 P$.

YIELDING, K. L. \& Tomkins, G. M. (1959). Inhibition of the enzymic oxidation of DPNH by steroid hormones. Proc. nat. Acad. Sci., Wash. 45, 1730. 